Journal of Applied Pharmaceutical Science Vol. 6 (10), pp. 147-153, October, 2016

Available online at http://www.japsonline.com

DOI: $10.7324 / \mathrm{JAPS} .2016 .601020$

ISSN 2231-3354 (cc) BY-NC-SA

\title{
Antinociceptive Ecdysteroids and Other Constituents of Palisota hirsuta K. Schum (Commelinaceae)
}

\author{
Francis Mainoo Sarpong ${ }^{1 *}$, Francis Ackah Armah², Isaac Kingsley Amponsah ${ }^{3}$, Philip Kobla Atchoglo ${ }^{4}$ \\ ${ }^{1}$ Department of Pharmaceutical Sciences, Faculty of Health Sciences, Kumasi Polytechnic, Kumasi, Ghana. ${ }^{2}$ Department of Biomedical Sciences, Faculty of Allied \\ Sciences, College of Health and Allied Health Sciences, University of Cape Coast, Cape Coast, Ghana. ${ }^{3}$ Department of Pharmacognosy, Faculty of Pharmacy and \\ Pharmaceutical Sciences, Kwame Nkrumah University of Science and Technology, Kumasi, Ghana. ${ }^{4}$ Department of Chemistry, College of Science, Kwame \\ Nkrumah University of Science and Technology, Kumasi, Ghana.
}

\section{ARTICLE INFO \\ Article history: \\ Received on: 07/08/2016 \\ Revised on: 06/09/2016 \\ Accepted on: 24/09/2016 \\ Available online: 29/10/2016}

\section{Key words :}

Formalin, Nociceptive, Inhibition, Isolates,

ecdysteroids.

\begin{abstract}
The root of Palisota hirsuta is used in Ghana and other West African countries for the treatment of various disease conditions such as rheumatoid arthritis (also in other inflammatory and painful conditions), infertility in females, anaemia, and dysentery. The current study sought to evaluate the anti-nociceptive effect of the hydroethanolic root extract and compounds isolated from Palisota hirsuta. Mice were used for studying the antinociceptive activity of $P$. hirsuta extracts and isolates at doses of $10-300 \mathrm{mgkg}-{ }^{1}$ p.o and $10-30 \mathrm{mgkg}^{-1}$ respectively using the Formalin Induced paw licking model. The total crude extract, methanolic and petroleum ether fractions showed analgesic activity in a dose-dependent manner for both the early and late phases. Three isolates, a fatty acid mixture, 20-hydroxyecdysone and an uncharacterized ecdysteroid (PH V) were obtained from the methanol fractions with significant activity. 20-hydroxyecdysone exhibited a dose-dependent inhibition of the nociception for both the early and late phases; $71.39 \pm 9.19 \%$ and $89.19 \pm 3.81 \%$ respectively. PH V showed significant activity between the early and late phases of inhibition as compared to the reference drug morphine. The present study has given scientific credence to the use of the roots of $P$. hirsuta for the mitigation of pain and established its antinociceptive constituents.
\end{abstract}

\section{INTRODUCTION}

Pain is a normal manifestation in everyday life and serves as a vital defensive function. However, uncontrolled pain can dramatically diminish quality of life (Page et al., 1997). It is an unpleasant sensation that can be either acute or chronic and is as a consequence of complex neurochemical process in the peripheral and central nervous system (Richard et al., 2012). Pain and inflammation is the most common manifestation of diseases that affect millions of people worldwide (Bhatia et al., 2013). According to a WHO report, about $70-80 \%$ of the world's populations rely on non-conventional medicines mainly from herbal sources in their primary health care. Plants are still the reservoirs for obtaining drugs and drug leads (Newman and

\footnotetext{
* Corresponding Author

Dr Francis Mainoo Sarpong, Faculty of Health Sciences, Department of Pharmaceutical Sciences, Kumasi Polytechnic, Kumasi, Ghana.

Email: sarps2003 @ yahoo.co.uk, Mobile:0277400529
}

Cragg, 2007) and are also a good source of anti-nociceptive compounds; morphine from Papaver somniferum L. (Papaveraceae).

Palisota hirsuta is used traditionally for its pain-relieving and antiseptic effects. The plant juice and crushed pieces of twigs are used as a poultice for fractures, bruises, joint pains, nail ulcers and lymph gland inflammation. The whole plant decoction is used for urethral problems. Leaf preparations are used against lice (Bellomaria and Kacou, 1995). Boakye-Gyasi et al., (2014), demonstrated that oral administration of an ethanolic leaf extract of Palisota hirsuta attenuates pain-related behavior in vincristineinduced neuropathic pain model. Sarpong et al., (2013) also showed that the roots of $P$. hirsuta and its constituents, mainly 20hydroxyecdysone, show anti-inflammatory and antioxidant activities. However, the root of Palisota hirsuta and its compounds have not being thoroughly evaluated for analgesic activity as suggested by folklore medicine. Therefore, the present study aimed at evaluating the possible anti-nociceptive activity of the 
hydroethanolic root extracts, isolate and characterise the antinociceptive constituents.

\section{MATERIALS AND METHODS}

\section{Plant collection and processing}

Palisota hirsuta roots were collected from EsaaseBontefufuom in the Amansie West district of Ashanti Region of Ghana, in May 2014. The plant was authenticated by Dr George Henry Sam of the Department of Herbal Medicine, Kwame Nkrumah University of Science and Technology; a voucher specimen was kept in the Faculty of Pharmacy and Pharmaceutical Sciences' Herbarium (No. FP 1008). The roots were washed and sun-dried for seven (7) days and then milled into coarse powder.

\section{Extraction}

The powdered roots of $P$. hirsuta $(2 \mathrm{~kg})$ was then soxhlet extracted with 4 litres of $70 \%$ ethanol. The crude extract (cristened, PHC), was then concentrated with a rotary evaporator (R-114, Buchi, Switzerland) at a temperature of $55^{\circ} \mathrm{C}$ under vacuum to give a yield of $200 \mathrm{~g}(11.69 \%$.). $100 \mathrm{~g}$ of the crude extract (PHC) was dissolved in $80 \%$ methanol and defatted with Petroleum ether $(\mathrm{BDH}) 40-60^{\circ} \mathrm{C}$ to afford an extract, PHE and the remaining methanol soluble extract as PHM.

\section{Chromatographic fractionation and isolation}

The methanol extract ( $60 \mathrm{~g})$ was adsorbed unto silica gel and loaded onto a glass column $(80 \mathrm{~cm} \mathrm{x} 5 \mathrm{~cm})$ packed with $400 \mathrm{~g}$ of silica gel (60-120 ASTM). The column was then eluted using gradient mixtures of petroleum ether/ethyl acetate (80:20), petroleum ether/ethyl acetate (50:50), ethyl acetate (100\%), ethyl acetate/methanol (80:20), ethyl acetate/methanol (50:50), ethyl acetate/methanol (20:80) and methanol (100\%). One hundred and fifty eluates were collected and bulked into four fractions (F1-4). The fractions were further column chromatographed according to the procedure described by Sarpong et al., 2013 to afford fraction $\mathrm{PH}_{1}$ (an oil containing mixtures of fatty acids), compound PH IV (20-hydroxy ecdysone) and an uncharacterized compound PH V.

\section{Experimental}

NMR and MS were employed as the techniques to identify the structure and identity of compounds in this project/study. ${ }^{1} \mathrm{H}$ NMR, ${ }^{13} \mathrm{C}$ NMR and 2D NMR (COSY, NOESY, HMQC and HMBC) spectra were obtained on a Bruker $400 \mathrm{MHz}$ instrument. One bond $1 \mathrm{H}-13 \mathrm{C}$ connectivities were determined with HSQC while two- and three-bond $1 \mathrm{H}-13 \mathrm{C}$ connectivities were determined by HMBC experiments. Chemical shifts were reported in $\delta$ (ppm) using the solvent (DMSO). GC-MS was also utilized to resolve the compounds which were mixtures of fatty acids and for that matter difficult to separate with silica gel.

\section{Anti-Nociceptive Activity of Extracts and Compounds}

Drugs: Formalin was obtained from BDH, Poole, England and Morphine hydrochloride was purchased from Phyto-Riker Pharmaceuticals, Accra, Ghana.
Animals: Mice [Imprinting Control Region (ICR)] (30-40g) were purchased from Centre for Scientific Research into Plant Medicine Akwapim Mampong, Ghana and housed in the animal facility of the Department of Pharmacology, Kwame Nkrumah University of Science and Technology (KNUST). The animals were housed in groups of six in stainless steel cages $(34 \times 47 \times 18 \mathrm{~cm})$ with soft wood shavings as bedding, fed with normal commercial pellet diet (GAFCO, Tema), given water ad libitum and maintained under laboratory conditions (temperature $24-28{ }^{\circ} \mathrm{C}$, relative humidity 60 $70 \%$, and 12 hour light-dark cycle). All procedures and techniques used in these studies were in accordance with the National Institute of Health Guidelines for the Care and Use of Laboratory Animals (NIH, Department of Health and Human Services publication no. 85 - 23, revised 1985). All protocols used were approved by the Department of Pharmacology Ethics Committee, KNUST, Kumasi.

\section{Formalin induced nociception}

The formalin test first described by Dubuisson and Dennis, (1977) was carried out as described by Malmberg and Yaksh, (1995) with a few modifications. Each animal was assigned and acclimatized to one of 20 formalin test chambers (a Perspex chamber $15 \times 15 \times 15 \mathrm{~cm}$ ) for thirty minutes before formalin injection (Wilson et al., 2002). The mice were then pretreated with the test drugs $(30 \mathrm{~min}$ for i.p. route and $1 \mathrm{hr}$ for oral route) before intraplantar injection of $10 \mu \mathrm{l}$ of $5 \%$ formalin. The animals were immediately returned individually into the testing chamber. A mirror angled at $45^{\circ}$ below the floor of the chamber allowed a complete view of the paws. The behaviour of the animal was then captured over a 60 minute period for analysis by a camcorder (Everio $^{\mathrm{TM}}$ model GZ-MG1300, JVC, Tokyo, Japan) placed in front of the mirror. Pain response was scored for $60 \mathrm{~min}$, starting immediately after formalin injection.

The first phase of the formalin test was defined conservatively as 0-10 minutes and the second phase 10-60 minutes post formalin injection (Wilson et al., 2002). Nociceptive behaviour was quantified by counting the incidents of spontaneous biting/licking of the injected paw (Zochodne et al., 2001) using the public domain software JWatcher ${ }^{\mathrm{TM}}$ Version 1.0 (University of California, Los Angeles, USA and Macquarie University, Sydney, Australia available at http://www.jwatcher.ucla.edu/). Nociceptive score was determined for each 5-mins time block in each phase by measuring the amount of time spent biting/licking the injected paw. The product of the frequency and duration of biting/licking was used as nociceptive score. Mice were randomly selected for one of the following study groups: Group I: Morphine (1, 3, and $10 \mathrm{mg} \mathrm{kg}^{-1}$ ), Group II: P. hirsuta extract, PHC (30, 100 and 300 $\mathrm{mg} \mathrm{kg}^{-1}$ ), Group III: Vehicle treated control, Group IV: Methanol fraction, PHM (30, 100 and $300 \mathrm{mg} \mathrm{kg}^{-1}$ ), Group V: Petroleum Ether Fraction, PHE (30, 100 and $300 \mathrm{mg} \mathrm{kg}^{-1}$ ), Group VI: PH IV (1, 10 and $30 \mathrm{mg} \mathrm{kg}^{-1}$ ), Group VII: PH V (1, 10 and $\left.30 \mathrm{mg} \mathrm{kg}^{-1}\right)$.

\section{Statistical Analysis}

The statistical analyses were performed by ANOVA, followed by Newman-Keuls post hoc tests using GraphPad Prism 
for Windows version 5 (GraphPad Software, San Diego, USA). The results were expressed as the mean \pm S.E.M to show variation in groups. Differences are considered significant when $\mathrm{P} \leq 0.05$.

\section{RESULTS}

\section{Anti-nociceptive Assay}

Formalin-induced nociception

Formalin administration produced a typical pattern of flinching and licking behaviour (Figures $1 \& 2$ ), produced a marked and dose-related inhibition of both phases of formalininduced nociception first phase $(P<0.0001)$ and second phase $(P$ $<0.0001$ ). The highest dose produced maximal inhibitions of $40.89 \pm 24.10 \%$ and $66.25 \pm 32.08 \%$ for the early and late phases of the crude extract PHC. For the pet-ether fraction, PHE the highest dose caused maximal nociceptive inhibition of $45.02 \pm 29.81 \%$ and $80.50 \pm 4.628 \%$. The maximal inhibitions caused by the highest dose of the methanol fraction PHM was $31.72 \pm 15.29 \%$ and $61.0 \pm 41.97 \%$ for the two phases.

Considering the isolates, the pattern of inhibition was not regular for the isolated compounds. For instance, with PH I, the maximal inhibitions caused by the doses (phase $1: 10 \mathrm{mgkg}^{-1}$ and phase 2: $30 \mathrm{mgkg}^{-1}$ ) were $55.08 \pm 14.90 \%$ and $63.57 \pm 25.91 \%$. The highest dose $\left(30 \mathrm{mgkg}^{-1}\right)$ caused maximal inhibitions of nociception of $71.39 \pm 9.192 \%$ and $89.19 \pm 3.816 \%$ for PH IV and $61.34 \pm 11.07 \%$ and $82.89 \pm 3.978 \%$ and for $\mathrm{PH} \mathrm{V}$ (Figure 2). Similarly, morphine $\left(1-10 \mathrm{mg} \mathrm{kg}^{-1}\right.$, i.p) produced marked inhibition of both the neurogenic $(\mathrm{P}<0.0001)$ and inflammatory $(\mathrm{P}$ $<0.0001$ ) pain phases (Figure 1a-b). Morphine, reduced the duration of formalin evoked nociceptive behavior by a maximum percentage of $92.49 \pm 4.679 \%$ in the early phase and $95.16 \pm 5.497 \%$ in the late phase of the formalin test (Figure 1a-b). Examining the results obtained in the formalin test, it was deduced that; PHC, PHE, PHM, PH I, IV, V and morphine significantly reduced the time spent in licking the injured paw, an indication that these compounds possess strong anti-nociceptive or analgesic properties.

\section{Identification of the compounds}

The fatty acid mixture PH-1 was subjected to GC/MS. Compounds were identified by their mass spectra, interpretation of their fragmentation patterns and comparing retention times of their peaks to those of standard compounds analysed previously in literature (National Institute of Standards and Technology (NIST), 2011). The fatty acid components were identified as hexanoic acid, stearic acid and eicosanoic acid as previously reported by Sarpong et al., (2013).

PH IV was isolated as an off white amorphous solid with a melting point of $240-242^{\circ} \mathrm{C}$ [Literature: $237.5-239.5^{\circ} \mathrm{C}$ ] (Hikino and Hikino, 1990). It showed positive Liebermann's test. The Electron Spray Ionization Mass Spectrometer(ESI-MS) revealed a molecular ion peak $[\mathrm{M}-\mathrm{H}]+$ at $\mathrm{m} / \mathrm{z}$ of 479 which corresponded to the molecular formular, indicating six degrees of unsaturation, ascribed to $\alpha, \beta$ - unsaturated ketone and four steroid rings (Yun-
Song et al., 2007).

The 1H-NMR revealed the presence of five methyl singlets at $\delta 0.76(\mathrm{H}-18), 0.83(\mathrm{H}-19), 1.06(\mathrm{H}-21), 1.05(\mathrm{H}-26)$ and $1.07(\mathrm{H}-27)$. The relatively downfield resonance of the last three signals revealed the presence of hydroxyl groups at C-20 and C-25 positions (i.e. OHd and $\mathrm{OHf}$ respectively). Other hydroxyl groups occurred at C-2, C-3, C-22 and the quaternary carbon C-14 (i.e. $\mathrm{OHa}, \mathrm{OHb}, \mathrm{OHe}$ and $\mathrm{OHc}$ respectively). The presence of the $\mathrm{OH}$ groups caused the methine protons $\mathrm{H}-2, \mathrm{H}-3$ and $\mathrm{H}-22$ to occur more downfield (at $\delta 3.52,3.76$ and 3.11) relative to other methine protons at $\delta 2.19(\mathrm{H}-5), 3.02(\mathrm{H}-9)$ and $2.23(\mathrm{H}-17)$. The cluster of signals in the region 1.09-2.01 ppm, revealed the presence of methylene protons of the steroid framework.

The ${ }^{13} \mathrm{C}$-NMR spectrum revealed the presence of twentyseven (27) carbon resonances. Five methyl signals occurred at $\delta$ 17.6 (C-18), 24.3 (C-19), 21.4 (C- 21), 30.8 (C-26) and 30.5 (C27). A carbonyl (ketone) group occurred at $\delta 203.13$ (C-6). The signals at 165.89 and $120.94 \mathrm{ppm}$ were assigned to the olefinic carbons C-8 and C-7 respectively. The presence of 27 carbon resonances including five methyl signals suggested that PH IV may be an analogue of cholesterol. Other carbons present in the spectrum included five quaternary carbon signals at $\delta 83.5,76.28$, $69.17,47.35$ and 38.1. The signals occurring more downfield at $\delta$ $83.5,76.2$ and 69.17 were assigned to the oxygenated carbons C$14, \mathrm{C}-20$ and $\mathrm{C}-25$ respectively. Other oxygenated carbon resonances occurred at $\delta 76.8$ (C-22), 67.25 (C-2), and 67.0 (C-3). Eight methylene carbon signals occurred at $\delta 37.1,32.0,21.4$, $31.34,29.5,20.6,26.6$ and $41.9 \mathrm{ppm}$ which were assigned to C-1, C-4, C-11, C-12, C-15, C-16 C-23 and C-24. Three methine signals occurred at $\delta 50.6(\mathrm{C}-5), 33.5(\mathrm{C}-9)$ and 49.2 (C- 17). All of the protonated carbons were assigned by heteronuclear single quantum correlation (HSQC) experiment.

In the HMBC spectrum, the olefinic proton $\mathrm{H}-7$ had $3 \mathrm{~J}$ correlations with C-5, C-9, and C-14. The proton signal H-5 had 2J correlation with the carbonyl C-6. This suggested the presence of a 7-en-6-one chromophore, characteristic of ecdysteroids (Mamadalieva, 2012). H-5 also coupled to C-9 (3J); H-19 to C-5 (3J), C-9 (3J) and H-9 to C-8 (3J) in HMBC. The methyl proton singlet $\delta 0.78(\mathrm{H}-18)$ had $2 \mathrm{~J}$ correlation with $\mathrm{C}-13$ and $3 \mathrm{~J}$ correlation with $\mathrm{C}-14$ and $\mathrm{C}-17$. The hydroxyl signal at $\delta 4.62$ $(\mathrm{OH})$ coupled in HMBC to both C-14 (2J) and C-13 (3J). Also the proton $\mathrm{H}-17$ had a $2 \mathrm{~J}$ and $3 \mathrm{~J}$ correlations with $\mathrm{C}-13$ and $\mathrm{C}-18 ; \mathrm{H}-$ 17 (3J) with $\mathrm{C}-14$ in long range correlation. The hydroxyl signal OHf had $3 \mathrm{~J}$ correlations with $\mathrm{C}-26$ and $\mathrm{C}-27$ and $2 \mathrm{~J}$ correlation with C-25. The methyl singlet $\mathrm{H}-26$ also coupled to $\mathrm{C}-27$ (3J) and C-25 (2J). H-27 also couples to C-26 (3J), C-25 (2J) and C-24 (3J). Also OHd coupled to C-20 (2J), C-22(3J) and C-17 (3J); methyl singlet $\mathrm{H}-21$ had $2 \mathrm{~J}$ and $3 \mathrm{~J}$ correlation with $\mathrm{C}-20$ and $\mathrm{C}-17$ respectively. OHe also coupled in $\mathrm{HMBC}$ to $\mathrm{C}-23$ (3J), C-20 (3J) and C-22 (2J). This established the partial side chain structure. $3 \mathrm{~J}$ correlation of OHd and H-21 with C-17 suggested that the side chain was attached to the steroidal nucleus at $\mathrm{C}-17$. 

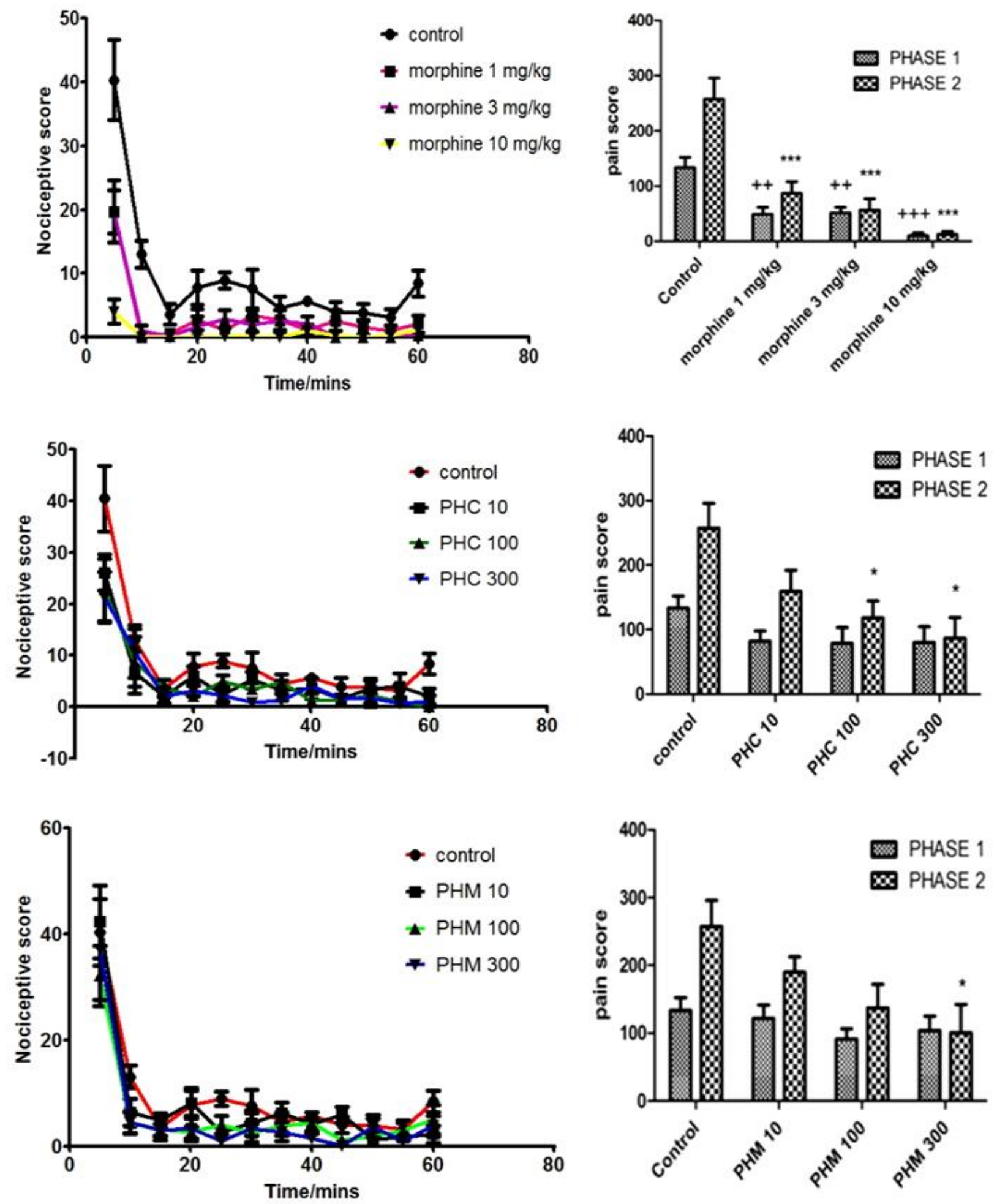

Fig. 1: Effect of Morphine (a-b) (1-10 mg kg-1 i.p.), PHC (10-300 $\left.\mathrm{mg} \mathrm{kg}^{-1} i . p ., c-d\right)$, PHM (10-300 $\mathrm{mg} \mathrm{kg}^{-1}$ i.p., e-f) on the time course of formalin induced pain in mice. Nociceptive/pain scores are shown in 5 min blocks up to 60 min post formalin injection. Each point represents Mean \pm S.E.M ( $\mathrm{n}=5$ ). $* P \leq 0.05, * * P \leq 0.01, * * * P \leq 0.001$ compared to respective controls (two-way repeated measures ANOVA; the AUC (total response) for phase 1 and phase 2 . Each column in b represents the mean \pm S.E.M. ${ }^{+} P \leq 0.05,{ }^{++} P \leq 0.01,{ }^{+++} P \leq 0.001$ (one-way ANOVA followed by NewmanKeuls post hoc test). 

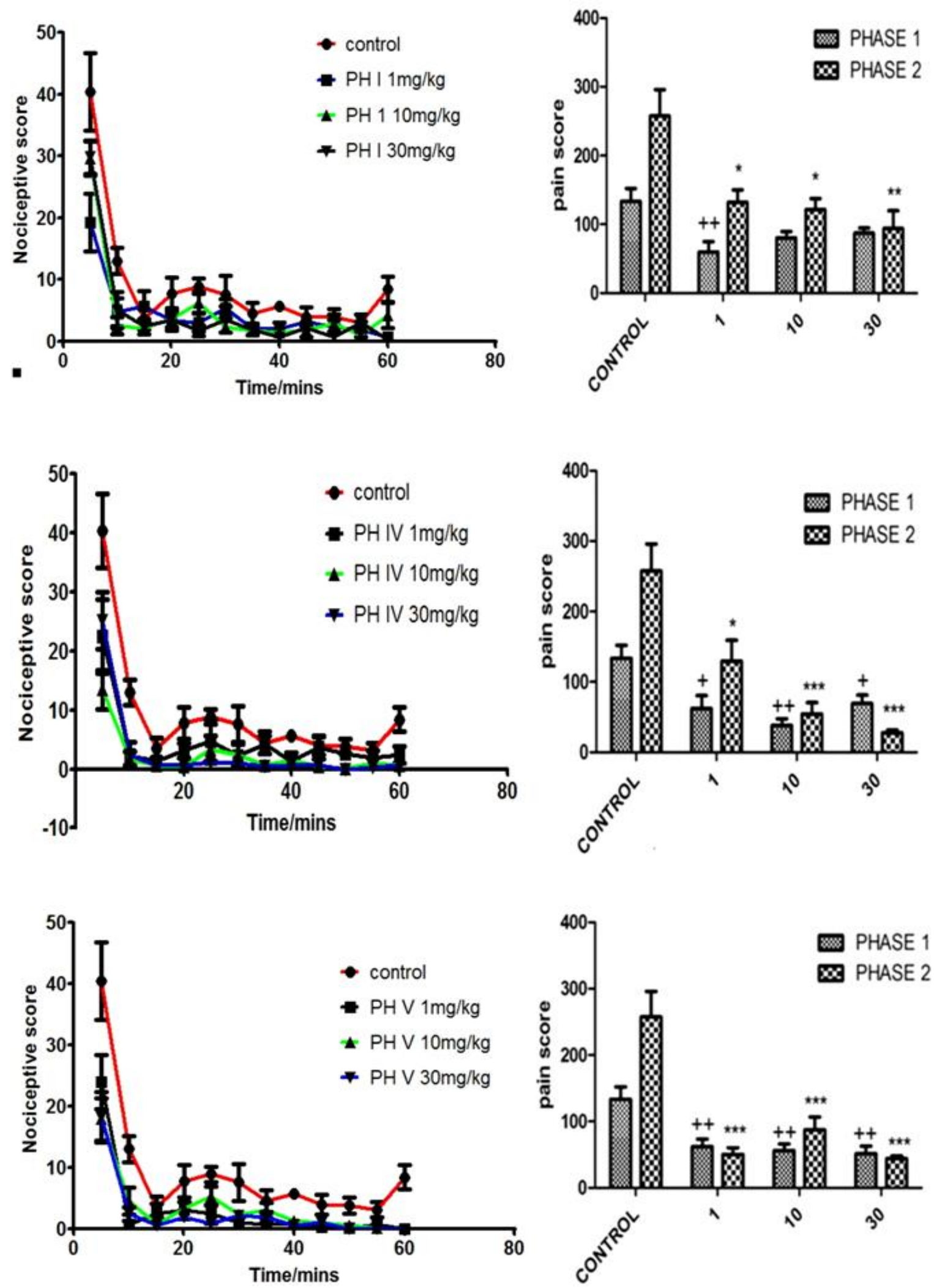

Fig. 2: Effect of PH I (1-30 mg kg ${ }^{-1}$ i.p.a-b), PH IV (c-d) and PH V (e-f) (1-30 $\mathrm{mg} \mathrm{kg}^{-1}$ i.p.) on the time course of formalin induced pain in mice. Nociceptive/pain scores are shown in 5 min blocks up to $60 \mathrm{~min}$ post formalin injection. Each point represents Mean \pm S.E.M (n $=5$ ). $* P \leq 0.05$, $* * P \leq$ $0.01, * * * P \leq 0.001$ compared to respective controls (two-way repeated measures ANOVA; the AUC (total response) for phase 1 and phase 2 . Each column in $\mathrm{b}$ represents the mean \pm S.E.M. ${ }^{+} P \leq 0.05,{ }^{++} P \leq 0.01,{ }^{+++} P \leq 0.001$ (one-way ANOVA followed by Newman-Keuls post hoc test). 


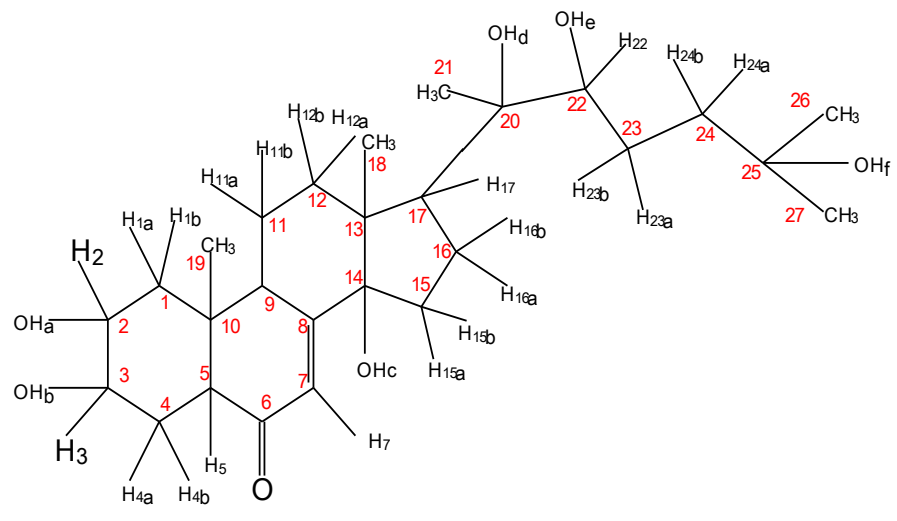

The ${ }^{1} \mathrm{H}-\mathrm{NMR}$ and ${ }^{13} \mathrm{C}-\mathrm{NMR}$ resonances of $\mathrm{PH} \mathrm{IV}$, all agreed with that published for 20-hydroxyecdysone, reported in the roots of Palisota hirsuta (Sarpong et al., 2013). PH V was not characterized due to ample NMR data. The preliminary phytochemical screening revealed $\mathrm{PH} \mathrm{V}$ to be a steroid and the molecular masses and the fragmentation pattern from the GC/MS spectral analyses suggested it to be an ecdysteroid.

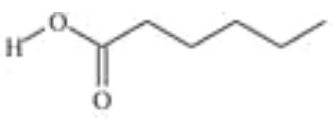

Hexanoic acid

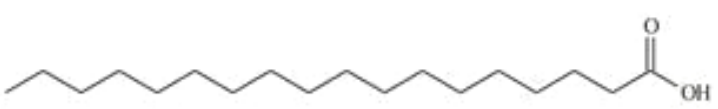

Stearic acid

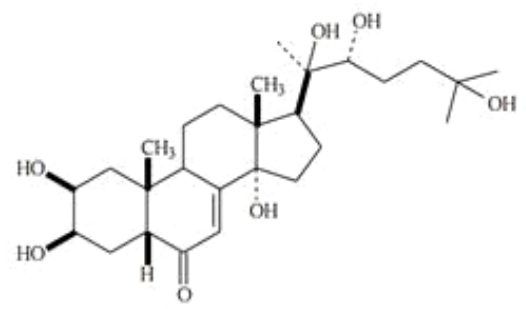

20-Hydroxyecdysone

\section{DISCUSSION}

In the formalin test, the early phase is considered to be due to direct activation of nociception neurons by formalin, whereas the late phase reflects pain generated in acutely injured tissue (Hunskaar and Hole, 1987; Tang et al, 2007). The licking response induced by formalin, results from a combination of peripheral input and spinal cord sensitization (Tjolsen et al., 1992). The intraplantar injection of formalin, releases prostaglandin $2\left(\mathrm{PGE}_{2}\right)$, nitrous oxide ( $\mathrm{NO}$ ) and kinins in the spinal cord (Tjolsen et al., 1992). Taking this into account, the anti-nociception of Palisota hirsuta could be dependent on either peripheral or central sites of action or both. Centrally acting drugs, such as opioids, inhibit both phases of pain by equally inhibiting the effect produced by prostaglandins released at this level in response to inflammation (Ferreira, 1981; Hunskaar and Hole, 1987; Shibata et $a l, 1989)$ and by endogenous opioids through their action on the central nervous system. It has been demonstrated (Tjolsen et al., 1992) that the late phase in formalin test depends on an inflammatory reaction in peripheral tissue. Peripheral acting drugs such as diclofenac (Rosland et al., 1990) which block prostaglandin synthesis, reduce nociception mostly in the late phase but can also affect the early stage (Ortiz et al., 2008). In fact, the anti-nociceptive effects of the extracts and compounds, exhibited in the formalin test, suggest an involvement at both central and peripheral levels, which further implies that the extract and the isolates possess not only anti-nociceptive but also antiinflammatory activity. This result therefore agrees with the antiinflammatory activity of $P$. hirsuta established by Sarpong et al., (2013).

From Figure 1a-f and 2a-f, there is the indication of maximal inhibitions or reductions of the licking time in the early and late phases, respectively. Similarly, morphine (1-10 $\mathrm{mg} \mathrm{kg}^{-1}$, i.p.) produced marked inhibition of both the neurogenic $(\mathrm{P}<0.0001)$ and inflammatory $(\mathrm{P}<0.0001)$ pain phases (Figure 1ab). Morphine, reduced the duration of formalin evoked nociceptive behavior by a maximum percentage of $92.49 \pm 4.67 \%$ in the early phase and $95.16 \pm 5.497 \%$ in the late phase of the formalin test (Figure 1a and b). The analgesic activity of 20-hydroxyecdysone (PH IV) was very much comparable to the standard drug morphine. The anti-nociceptive actions of the fractions and various isolates of the roots of Palisota hirsuta are being reported for the first time. From the results obtained, the anti-nociceptive properties of Palisota hirsuta are not in doubt due to the steroidal nature of the compounds found in the plant. Thus this research has shown that the root extract and its steroidal compounds have profound analgesic effects. However, the anti-nociceptive action is not dose dependent for the extract, fractions and the isolates used for the study. Woode et al., (2009), previously demonstrated the antinociceptive effect of $P$. hirsuta leaf extract. They highlighted that the analgesic effect of $P$. hirsuta might partially or wholly be due to the stimulation of peripheral opioid receptors through the activation of the nitric oxide-cyclic GMP-ATP-sensitive $\mathrm{K}^{+}$ (NO/cGMP/K $\mathrm{K}^{+} \mathrm{ATP}$ )-channel pathway without tolerance induction after chronic administration. This gives scientific credence to the use of the whole plant for treatment of pain and inflammatory conditions in folklore medicine.

Phytoecdysteroids have received attention as anabolic steroids. Chermnykh et al., (1988) compared the anabolic activities of 20-hydroxyecdysone and that of metandrostenolone and found the former to increase protein and carbohydrate metabolism and was non-toxic to the reproductive organs. Another ecdysteroid, ecdysterone, has also been reported to exhibit potent oxytocic activity in the guinea pig uterus assay besides inhibiting nicotine and serotonin-induced contractions during guinea pig ileum assay (Parameswaran et al, 2001) and may have some implication in the folkloric use to treat infertility. There is ample evidence of the varied biological activities of the ecdysteroids especially 20-hydroxyecdystone, however this is the first time the anti-nociceptive activity has been established. 


\section{CONCLUSION}

The roots of Palisota hirsuta contain ecdysteroids which are responsible for the treatment of pain. This also supports the claims of traditional medicine practitioners. The ethanolic root extract, methanolic and petroleum ether fractions and the isolates (fatty acids and 20-hydroxy ecdysone) of Palisota hirsuta have potent anti-nociceptive/analgesic activities.

\section{Financial support and sponsorship: Nil.}

Conflict of Interests: There are no conflicts of interest.

\section{REFERENCES}

Bellomaria B and Kacou P. Plants et Medicine Populaire d'Agboville(Cote D'Ivoire). Fitoterapia LXVI, 1995: 117-141.

Bhatia D, Bejarano T, Novo M. Current interventions in the management of knee osteoarthritis. J Pharm Bioallied Sci. 2013; 5(1):3038 .

Boakye-Gyasi E, Kasanga EA, Biney RP, Abotsi WKM, Mensah KB and Woode E. Ameliorative Effects of Ethanolic Leaf Extract of Palisota hirsuta K. Schum (Commelinaceae) on Vincristine-Induced Neuropathic Pain in rats. Journal of Applied Pharmaceutical Science, 2014; 4 (11): 035-041

Chermnykh NS, Shimanovsky NL, Shutko GV, Syrov VN. The action of methandrostenolone and ecdysterone on the physical endurance of animals and on protein metabolism in the skeletal muscles. Farmakol. Toksikol., 1988; 51(6):57-60.

Dubuisson D and Dennis SG. The formalin tests: a quantitative study of the analgesic effects of morphine, meperidine and brain stem stimulation in rats and cats. Pain, 1977; 4: 161-74.

Ferreira SH. Local control of inflammatory pain. Agents Actions, 1982; 11(6-7): 636-638

Hikino $\mathrm{H}$, and Hikino, Y. Arthropod moulting hormones. Progress in Chemistry of Organic Natural Products, 1990; 28:256-312.

Hunskaar S, and Hole K. The formalin test in mice: dissociation between inflammatory and non-inflammatory pain. Pain, 1987; 30(1): 103 114

Malmberg $\mathrm{AB}$ and Yaksh TL. Cyclooxygenase inhibition and the spinal release of prostaglandin E2 and amino acids evoked by paw formalin injection: a microdialysis study in unanaesthetized rats. J.Neurosci, 1995; 15: 2768-2776.

Mamadalieva, NZ. Phytoecdysteroids from Silene plants: distribution, diversity and biological (antitumour, antibacterial and antioxidant) activities. Boletín Latinoamericano y del Caribe de Plantas Medicinales y Aromáticas, 2012; 11(6):474-497.

Newman DJ, Cragg GM. Natural Pproducts as sources of New Drugs over the last 25 years. J Nat Prod., 2007; 70 (3):461-77

Ortiz MI, Lozano-Cuenca J, Granados-Soto V, CastañedaHernández G. Additive interaction between peripheral and central mechanisms involved in the antinociceptive effect of diclofenac in the formalin test in rats. Pharmacol Biochem Behav., 2008; 91(1):32-7.
PageCP, Curtis MJ, Sutter MC, Walker MJA, Hoffman BB. 1997. Integrated Pharmacology, Mosby Inc.; London. p. 306-310.

Parameswaran, P.S.; Naik, C.G.; Gonsalves, C.; Achuthankutty, C.T. Isolation of 2 deoxyecdysterone, a novel oxytocic agent, from a marine Zoanthus sp. J.Indian Inst.Sci., 2001; 81: 169-173.

Richard F, Michelle AC, Luigi XC. Opioids.2001. In: Richard AH, Pamela CC. (edited) Lipinncott's Illustrated Reviews. Lipinncott Williams and Wilkins Philadelphia, 2009; 4th ed:159.

Rosland JH, Tjolsen A, Maehle B, Hole K. The formalin test in mice: effect of formalin concentration. Pain, 1990; 42(2): 235-242.

Sarpong FM, Fleischer TC, Annan K, Amponsah IK, Dickson RA and Mensah MLK. Anti-inflammatory and anti-oxidant ecdysteroid and Fatty acids from the roots of Palisotahirsuta K.Schum (Commelinaceae). International Journal of Pharmacognosy and Phytochemistry, 2013: 28(2):1159-1165.

Shibata M, Ohkubo T, Takahashi H, Inoki R. Modified formalin test:characterisic biphasic pain response. Pain, 1989; 38(3): 347-352.

Tang L, Chen Y, Zili Chen Z, Blumberg PM, Kozikowski AP and Wang ZJ. Anti-nociceptive pharmacology of N-(4-chlorobenzyl)-N(4-hydroxy-3-iodo-5-methoxybenzyl)thio urea,a high-affinity competitive antagonist of the transient receptor potential vanilloid 1 receptor. J Pharmacol Exp Ther, 2007; 321(2): 791-798.

Tjolsen A, BergeOG, Hunskaar S, Rosland JH, Hole K. The formalin test: an evaluation of the method. Pain, 1992; 51(1): 5-17.

Wilson SG, Chesler EJ, Hain H, Rankin AJ, Schwarz JZ, Call SB, Murray MR, West EE, Teuscher C, Rodriguez-Zas S, Belknap JK, Mogil JS. Identification of quantitative trait loci for chemical/inflammatory nociception in mice. Pain, 2002; 96(3): 385-91.

Woode E, Boakye-Gyasi E, Ainooson GK, Ansah C and Duwiejua M. Anti-Nociceptive Effects and the Mechanism of Palisota hirsuta K. Schum. Leaf Extract in Murine Models. Int. J. Pharm., 2009; 5: 101-113.

Yun-Song W, Ying-Tong D, Hong-Ping H, Liang-Bo L, Yang L, Jian-Bo G, Xin F, Ning-Chuan K, Shun-Lin L, Hua-Jie Z and XiaoJiang $\mathrm{H}$. Isolation, $\mathrm{X}$-ray crystallography and computational studies of calydaphninone, a new alkaloid from Daphniphyllum calycillum. Org. Lett., 2007; 9(7): 1355-1358.

Zochodne DW, Sun H, Li X-Q. Evidence that nitric oxide- and opioid-containing interneurons innervate vessels in the dorsal horn of the spinal cord of rats. J. Physiol., 2001; 532(Pt 3):749-758.

How to cite this article:

Sarpong FM, Armah FA, Amponsah IK, Atchoglo PK. Antinociceptive Ecdysteroids and Other Constituents of Palisota hirsuta K.Schum (Commelinaceae). J App Pharm Sci, 2016; 6 (10): 147-153. 